\title{
Evaluation of peripheral nerves of upper limb and its correlation with blood sugar levels: A electrophysiological study in type 2 diabetics
}

\author{
Neelam Bala Prasad ${ }^{1, *}$, S.A. Diwanji ${ }^{2}$ \\ ${ }^{1}$ Professor, ${ }^{2}$ Ex Professor, Dept. of Physiology, Dr. D. Y. Patil Medical College, Hospital and Research Center, Dr. D.Y. Patil \\ Vidyapeeth, Pimpri, Pune, Maharashtra, India \\ *Corresponding Author: \\ Email: neelamprasad8@gmail.com
}

Received: $15^{\text {th }}$ October, 2017

Accepted: $10^{\text {th }}$ May, 2018

\begin{abstract}
Introduction: Peripheral neuropathy is a complication of diabetes which causes considerable indisposition and frailty. Metabolic derangement in diabetes affects nerve.

Aim: To carry out electrophysiological study of nerves in diabetics and to correlate it with blood sugar

Materials and Methods: Nerves of upper limb were assessed for motor nerve conduction with the help of surface electrodes and windows based (Neuro perfect software) computerized system in 50 type 2 diabetic male patients and 50 healthy males. The nerves chosen for study were median and ulnar. Parameters studied were distal latency and conduction velocity.

Results: Observation revealed increased distal latency and decreased conduction velocity in diabetics with statistically significant difference. These parameters also showed association with blood sugar levels in diabetics.

Conclusions: Diabetes affect nerves as indicated by declined motor nerve function through electrophysiological testing. Elevated blood sugar levels are related with nerve damage.
\end{abstract}

Keywords: Peripheral neuropathy, Diabetes, Electrophysiological tests, Conduction velocity.

\section{Introduction}

People suffering with diabetes in the world are increasing day by day and are expected to be roughly double between 2000 and 2030. ${ }^{1}$ With this increase in number there is possibility of increased prevalence of its complications. Deranged metabolism plays an important role in disease related complications. ${ }^{2}$ Diabetic neuropathy is one of its complications which involve all somatic nerves of the feet and hands. It usually progress gradually with unapparent symptoms. ${ }^{3}$ Nerve conduction studies (NCS) offer objective and quantitative measure of nerve function. It helps in evaluation of peripheral neuropathies and also in predicting the prognosis of neuropathy, ${ }^{4}$ hence it can be regularly used to know normal peripheral nerve functions. The present study was designed to detect the existence of early changes in peripheral nerves by NCS.

\section{Materials and Methods}

After taking institutional ethical clearance, a study was performed on 50 type 2 diabetic male patients with mean duration of disease $6 \pm 2.5$ years and 50 healthy control male volunteers. Peripheral nerves (Median and Ulnar) of upper limb were assessed for motor nerve conduction with the help of surface electrodes and windows based computerized EMG/ NCV/EP Mark II system (Neuro perfect software). This study was conducted in the Department of Physiology of Dr. D. Y. Patil Medical College, Hospital, and Research Center, Pimpri, Pune, India, on patients of Type 2 diabetes mellitus attending the diabetic clinic. Design of the study was cross-sectional.
Detailed clinical examinations of all the subjects were carried out. Any subject suffering from chronic illness, retinopathy, nephropathy, known neuropathic case, myopathy, alcoholic and smokers were excluded. Study details were explained to the subjects and informed consent was obtained from each of them. Height and weight measurements were taken and blood samples were collected for blood sugar estimation. Left median and left ulnar nerves of the subjects were chosen for motor nerve conduction study. NCS was performed at room temperature $\left(24-26{ }^{0} \mathrm{C}\right)$. Peripheral nerves were electrically stimulated by supra maximal stimulation and compound muscle action potentials (CMAP) were recorded from the muscle supplied by these nerves. Instrument calibrations for the recordings were: sensitivity: $2-5 \mathrm{mV} / \mathrm{mm}$, low frequency filter: $2-5$ $\mathrm{Hz}$, high frequency filter: $10 \mathrm{KHz}$ and sweep speed: 1-2 $\mathrm{ms} / \mathrm{mm}$. Both the nerves were stimulated at two sites (distal site and proximal site) and latencies were recorded in milliseconds. The time taken for the electrical impulse to travel from the stimulation site to the recording site is called latency. Distal latency and proximal latency were obtained and were used to calculate conduction velocity.

For median nerve motor conduction study, stimulation was given first at the middle of the wrist (distal stimulation) then at the elbow at the anterior cubital fossa over the brachial artery pulse (proximal stimulation). Recording of CMAP was obtained from abductor pollicis brevis. Ground electrode was placed between stimulating and recording electrodes. Distance between wrist and elbow was measured in millimeters. 
Conduction velocity of nerve was calculated by dividing this distance with the difference between two latencies and expressed in meters/second. For ulnar nerve, distal stimulation was given on medial aspect of wrist and the proximal stimulation was given at the elbow slightly above the ulnar groove. Recording was obtained from the belly of the abductor digitorum $\mathrm{V}$ muscle. Ground electrode was placed between stimulating and recording electrodes. Distance between two stimulations was measured in millimeters and conduction velocity was calculated. ${ }^{5}$

Data was statistical analyzed by Microsoft office Excel 2010 and t test. Correlations were examined by Pearson correlation coefficient.

\section{Results}

The results of the present study are summarized as follows. Table 1 shows anthropometric measurements and blood sugar levels of all the subjects. Mean age of diabetic group was significantly more than control group. Table 2 shows observation of motor nerve conduction study. Significantly higher distal latencies of nerves $(\mathrm{p}<0.001)$ were observed in diabetics. Lower conduction velocities $(p<0.001)$ of nerves were seen in diabetics. Distal latency shows positive correlation and conduction velocity shows negative correlation with blood sugar levels as shown in table 3 .

Table 1: Baseline anthropometric data and blood sugar levels of Diabetics and Controls

\begin{tabular}{|l|c|c|c|c|}
\hline Characteristics & $\begin{array}{c}\text { Diabetics } \\
\text { Mean } \pm \text { SD }\end{array}$ & $\begin{array}{c}\text { Controls } \\
\text { Mean } \pm \text { SD }\end{array}$ & p value & Significance \\
\hline Participants(n) & 50 & 50 & & \\
\hline Age(years) & $56 \pm 6$ & $51.7 \pm 6$ & 0.001 & HS \\
\hline Weight(Kg) & $73 \pm 14$ & $68 \pm 13$ & 0.079 & NS \\
\hline Height(Meters) & $1.7 \pm 0.04$ & $1.69 \pm 0.04$ & 0.365 & NS \\
\hline Fasting plasma glucose (mg\%) & $140 \pm 14.56$ & $90 \pm 8.53$ & 0.0000 & HS \\
\hline 2-hour plasma glucose (mg\%) & $227 \pm 23$ & $126.55 \pm 11.63$ & 0.0000 & HS \\
\hline
\end{tabular}

$* \mathrm{P}<0.001$ statistically highly significant.(HS) $* *$ NS: Not significant

Table 2: Nerve conduction study parameters

\begin{tabular}{|l|c|c|c|c|c|}
\hline \multicolumn{1}{|c|}{ Parameters } & Nerves & $\begin{array}{c}\text { Diabetics } \\
\text { Mean } \pm \text { SD }\end{array}$ & $\begin{array}{c}\text { Controls } \\
\text { Mean } \pm \text { SD }\end{array}$ & p value & Significance \\
\hline \multirow{2}{*}{ Distal Latency(in ms) } & Median & $2.9 \pm 0.6$ & $2.2 \pm 0.5$ & 0.000 & HS \\
\cline { 2 - 6 } & Ulnar & $1.7 \pm 0.4$ & $1.4 \pm 0.6$ & 0.009 & HS \\
\hline $\begin{array}{l}\text { Conduction velocity(in } \\
\mathrm{m} / \mathrm{s})\end{array}$ & Median & $53.2 \pm 5$ & $58 \pm 5.6$ & 0.000 & HS \\
\cline { 2 - 6 } & Ulnar & $53.1 \pm 10$ & $63.7 \pm 9$ & 0.000 & HS \\
\hline
\end{tabular}

$* * \mathrm{P}<0.001$ statistically highly significant (HS). Unit- ms: milliseconds, $\mathrm{m} / \mathrm{s}$ : meters per second

Table 3: Correlation of nerve conduction study parameters with Blood Sugar in Diabetics

\begin{tabular}{|l|c|c|c|}
\hline Parameters & Nerves & Fasting blood sugar & PP blood sugar \\
\cline { 3 - 4 } & & $\begin{array}{c}\text { Pearson correlation } \\
(\mathbf{r} \text { value })\end{array}$ & $\begin{array}{c}\text { Pearson correlation } \\
\text { (r value) }\end{array}$ \\
\hline \multirow{2}{*}{ Distal Latency } & Median & +0.08 & +0.18 \\
\cline { 2 - 4 } & Ulnar & +0.02 & +0.28 \\
\hline \multirow{2}{*}{ Conduction velocity } & Median & -0.18 & -0.2 \\
\cline { 2 - 4 } & Ulnar & -0.08 & -0.25 \\
\hline
\end{tabular}

\section{Discussion}

Significantly higher distal latency and lower conduction velocities of the nerves were observed in diabetics. Increased distil latency and decreased conduction velocity is suggestive of features of demyelination. This study also observed positive correlation of distal latency and negative correlation of conduction velocity with blood sugar levels in diabetics.

Sultana $\mathrm{S}$ et.al when carried out nerve conduction study on diabetic patients they also found reduced conduction velocity of motor nerves, similar to our findings. ${ }^{6}$ Reduced conduction velocity of lower limbs nerves in diabetics were also noticed by Kimura $\mathrm{J}$ et $\mathrm{al}^{7}$ and W. Hoffman et al. ${ }^{8}$ Kimura $\mathbf{J}$ et al also recorded increased latency in lower limb nerves in diabetics.

There is increase in the flux of sugar molecules through polyol pathway due to high glucose levels in diabetics, as a result sorbitol gets accumulated in the cells and causes osmotic stress. The formation of advanced glycation end products (AGE) and osmotic stress is one of the fundamental mechanisms in the development of diabetic microvascular complications. The accurate nature of injury to the peripheral nerves from hyperglycemia is still not been recognized but probably is related to mechanisms such as polyol accumulation, injury from AGEs and oxidative stress. ${ }^{9}$ 
However many studies have related dyslipidemia as one of the underlying pathophysiology behind the development of neuropathy. Abnormal serum lipids might facilitate nerve infarction through fat embolism or else lipid encouraged platelet aggregation. ${ }^{10}$ It has also been suggested that neuropathy in diabetes involves neuronal insulin deficiency/resistance and is not essentially strictly glucocentric. ${ }^{11}$

In the present study mean age of diabetics were significantly more than control group. Progressing age is said to be a strong risk factor for diabetic neuropathy, independent of the duration of diabetes and glycemic control. Several biological alterations occurring during the aging process which may account for the facilitating effect of age on diabetic neuropathy. ${ }^{12}$

The studies have shown that longest nerve fibers in the legs are affected due to diabetes. ${ }^{13,14}$ Most of the studies are carried out in lower limbs. Upper limb nerves are less studied and hence more studies are required to be carried out for advance evaluation.

The study had certain limitations. We did not attempt to correlate dyslipidemia with nerve conduction parameters. Further diabetic neuropathy usually affect both sensory and motor nerves, so recording of sensory nerve action potentials along with compound muscle action potentials would have been more useful in evaluation of nerve functions.

Recognizing the earliest alteration of nerve in diabetes is important and useful for setting diagnosis criteria in diabetic patients. Thus this study will help to make early diagnosis of diabetic neuropathy. This will further help in management and prognosis of diabetic neuropathy.

\section{Conclusion}

Diabetes affect nerves as indicated by declined motor nerve function through electrophysiological testing. Elevated blood sugar levels are related with nerve damage.

\section{References}

1. Lt Col MM Arora, Lt Col Yogesh Chander, Col Ramji Rai. Diabetes Mellitus in India- Y2K NOT OK. MJAFI. 2000;56(1):01-02.

2. P. Reed Larsen, M Henry, Shlomo Melmed, S Kenneth. Williams Textbook of endocrinology. 10 Ed. 2003; Saunders an Imprint of Elsevier. Philadelphia, Pennsylvania 19106: Page No.14271483 and1513-1554
3. Perkins BA, Olaleye D, Zinman B, Bril V. Simple screening tests for peripheral neuropathy in the diabetes clinic. Diabetes Care. 2001;24(2):250-6.

4. Gozani SN, Fisher MA, Kong X, Megerian JT, Rutkove SB. Electrodiagnostic automation: principles and practice. Phys Med Rehabil Clin N Am. 2005;16(4):101532.

5. UK Mishra and J Kalita. Clinical Neuophysiology. 2nd Ed. B.I. Churchill Livingstone Pvt. Ltd. New Delhi.1999

6. Sultana S, Begum N, Ali L, Hossain MM, Bhowmik NB, Parveen Z. Electrophysiological changes of motor nerves in patients with type 2 diabetes mellitus. JAFMC Bangladesh. 2009;5(5):14-17.

7. Kimura J, Yamada T, Stevland NP. Distal slowing of motor nerve conduction velocity in diabetic polyneuropathy. J Neurol Sci. 1979 Jul;42(2):291-302.

8. W. Hoffman, Z Hart, R Frank. Correlates of delayed motor nerve conduction and retinopathy in juvenile-onset diabetes mellitus. The journal of Pediatrics. 2009;102(3):351-356.

9. Gabbay KH: Aldose reductase inhibition in the treatment of diabetic neuropathy: where are we in 2004? Curr Diab Rep. 2004;405-408.

10. Aravindan PD, Lioyed M. Scalp Pain and Hyperlipidemia Int. J lin Pract. 2000;54(7):478-90.

11. Kim B and Feldman EL. Insulin resistance in the nervous system. Trends Endocrinol Metab. 2012;23:133-141.

12. Belmin J, Valensi P. Diabetic neuropathy in elderly patients. What can be done? Drugs \& Aging. 1996 Jun;8(6):416-29.

13. Lamontagne, A., and Buchthal, F. Electrophysiological studies in diabetic neuropathy. Journal of Neurology, Neurosurgery, and Psychiatry. 1970;33:442-452.

14. M. Baba and I. Ozaki. Electrophysiological Changes in Diabetic Neuropathy: From Subclinical Alterations to Disabling Abnormalities. Archives of Physiology and Biochemistry. 2001;109(3):234-240.

How to cite this article: Prasad NB, Diwanji SA. Evaluation of peripheral nerves of upper limb and its correlation with blood sugar levels: A electrophysiological study in type 2 diabetics. Ind $\mathbf{J}$ Clin Anat Physiol. 2018;5(3):344-346. 